RU Факторы, влияющие на употребление анафорического местоимения 3-го лица после неопределенного местоимения «что-то»

Буров Э. Е.

\begin{abstract}
Аннотация. Цель исследования - выявить ограничения на употребление анафорического местоимения 3-го лица после неопределенного местоимения «что-то». В статье анализируются результаты эксперимента, в ходе которого носителям русского языка нужно было оценить предложения, содержащие анафорическое «оно» с антецедентом «что-то», с точки зрения правильности употребления в каждом из них местоимения «оно». Устанавливаются статистически значимые зависимости оценок, данных респондентами, от контекстных характеристик местоимений «что-то» и «оно». Эти зависимости получают лингвистическое объяснение. Научная новизна состоит в исследовании местоимения «что-то» как антецедента местоимения 3-го лица. В результате обнаружено, что употреблению анафорического «оно» после «что-то» способствуют подлежащная позиция местоимения «что-то» и осмысление референта местоимения «оно» как чего-то таинственного и одушевленного.
\end{abstract}

\title{
Factors Influencing the Usage of a Third-Person Anaphoric Pronoun after the Indefinite Pronoun "Что-то (Something)"
}

Burov E. E.

\begin{abstract}
The paper aims to identify the restrictions on the use of a third-person anaphoric pronoun after the indefinite pronoun "что-то (something)". The article analyzes the results of a linguistic experiment during which Russian language bearers were asked to assess the correctness of pronoun "оно (it)" usage in the sentences containing anaphoric "оно (it)" with the antecedent "что-то (something)". The author shows that respondents' choices are determined by contextual characteristics of pronouns "что-то (something)" and "оно (it)". These dependences are justified from a linguistic viewpoint. Scientific originality of the study lies in the fact that pronoun "что-то (something)" is considered as the antecedent of a thirdperson pronoun. The research findings are as follows: the author identifies the factors determining the use of anaphoric "оно (it)" after "что-то (something)" - subject position of a pronoun "что-то (something)" and perception of pronoun "оно (it)" referent as something mysterious and animated.
\end{abstract}

\section{Введение}

В последние десятилетия активно исследуются русские неопределенные местоимения. В работах Е. В. Падучевой (1985; Зализняк, Падучева, 2019), А. Д. Шмелева (2002), Л. А. Синько (2011), О. Д. Третьяковой (2009), Анны. А. Зализняк (Зализняк, Падучева, 2019), А. Л. Бегляровой (2011), Л. А. Горшковой (2009) рассматриваются референциальные, дискурсивные, стилистические свойства этих слов. Однако, как представляется, русские неопределенные местоимения до сих пор не получили исчерпывающего и непротиворечивого описания. В частности, не стало предметом специального изучения их участие в анафорических отношениях, в то время как «теория анафоры представляет собой одно из наиболее интенсивно развивающихся направлений современной лингвистики» (Сигал, 2017, с. 77). Вышеизложенное свидетельствует об актуальности темы исследования.

Е. В. Падучева (1985) в монографии «Высказывание и его соотнесенность с действительностью (Референциальные аспекты семантики местоимений)» отмечает: «Местоимения кто-то, что-то характеризуются ограниченными возможностями выступать в роли антецедента местоимения 3-го лица» (с. 212). Этому нетривиальному наблюдению не дается, однако, лингвистического объяснения; кроме того, не уточняется, какие именно ограничения действуют.

Научная статья (original research article) । https://doi.org/10.30853/phil210536

(๔) 2021 Авторы. 000 Издательство «Грамота» (๔ 2021 The Authors. GRAMOTA Publishers). Открытый доступ предоставляется на условиях лицензии СС ВY 4.0 (open access article under the CС BY 4.0 license): https://creativecommons.org/licenses/by/4.0/ 
Для достижения цели исследования необходимо решить следующие задачи: во-первых, получить примеры контекстов, в которых употребление анафорического оно после что-то приемлемо для носителей языка, и примеры контекстов, в которых такое употребление неприемлемо; во-вторых, выявить такие характеристики местоимений что-то и оно, которые специфичны для приемлемых контекстов, и такие характеристики этих местоимений, которые специфичны для контекстов неприемлемых; в-третьих, попытаться дать лингвистическое объяснение влиянию выявленных характеристик местоимений что-то и оно на приемлемость/неприемлемость анафорического местоимения.

Основные методы исследования: метод лингвистического эксперимента и статистические методы. Эксперимент необходим, чтобы получить оценку контекстов, содержащих анафорическое оно с антецедентом что-то, как приемлемых или неприемлемых с точки зрения «среднего» носителя русского языка, то есть для решения первой из указанных задач. Статистические методы дают возможность решить вторую задачу: именно благодаря им выявляются такие зависимости между характеристиками местоимений что-то и оно в исследуемых контекстах и приемлемостью/неприемлемостью (с точки зрения «среднего» носителя русского языка) употребления анафорического оно в этих контекстах, которые являются значимыми, неслучайными.

Теоретической базой исследования служат работы Е. В. Падучевой (1985; 2016), А. А. Кибрика (1987), А. Д. Шмелева (2002), в которых рассматриваются проблемы референции и анафоры, референциальные аспекты семантики местоимений.

Практическая значимость исследования заключается в том, что его результаты могут быть использованы в педагогической деятельности, в частности при преподавании русского языка как иностранного, а также при разработке спецкурса по семантике местоимений.

\section{Основная часть}

\section{Описание проведенного лингвистического эксперимента}

Первым этапом исследования стало проведение лингвистического эксперимента. Носителям русского языка, в основном студентам Института филологии, иностранных языков и медиакоммуникации Иркутского государственного университета, было предложено через сервис «Google Формы» оценить следующие 16 предложений, в каждом из которых после что-то употребляется анафорическое оно:

1. Было в каждом из них что-то свое, особенное, но - неясное, неуловимое - оно не задевало души.

2. На второе было что-то тоже вкусное, но как оно называется, Руська не знал.

3. Наверное, что-то совершается в ней, и совершится оно само.

4. Он швырнул что-то на стол; тускло звякнуло оно, как полтинник.

5. Она мечтала о чем-то большом, доступном ей и все-таки неясном, надеясь лишь, что, приди оно, оно бы в ней не обманулось.

6. Он тащил сани-волокушу; на них, покачиваясь, сползая с дороги, плыло что-то, еще огромней его, малиновокрасное; когда приблизилось оно, стало видно, что это товарный вагон без колес, прикрученный ржавыми тросами.

7. Порою в словах Софьи вдруг являлось что-то резкое, оно казалось матери лишним и возбуждало у нее опасливую думу.

8. Сказка скоро кончилась, все тайны были открыты, а если и выпадало иной раз что-то еще удивительное, то оно догоняло, казалось, из прошлого, из того, что в спешке было пропущено по пути.

9. У него в голове, в самой глубине мозга, начало что-то отворяться; это что-то влекло его, а когда оно совсем отворилось, его сознание устремилось навстречу тому, что ему открылось.

10. Успех - это когда что-то строишь, и оно востребовано.

11. Чтобы что-то было сломано, оно должно быть сначала построено.

12. Что-то глубокое и горькое открылось мне вдруг в нашем сиденье на кухне, и меньще всего касалось оно личной нашей судьбы.

13. Что-то находилось совсем рядом, оно могло броситься на него в любой момент.

14. Что-то тонкое, шершавое, плоское, ледяное, липкое и живое обвивалось во мраке вокруг его обнаженной руки; оно подбиралось к его груди, оно сжимало ремнем, впивалось буравом.

15. Что-то уже случилось и произошло в мире, но коснулось ли оно меня?

16. Чувствует, что надо говорить что-то такое веселое, бодрое, а как оно говорится, не знает.

Респонденты отвечали на вопрос о том, насколько приемлемо в каждом из предложений использовать местоимение оно.

Предложения были отобраны случайным образом из тех результатов, которые Национальный корпус русского языка (Национальный корпус русского языка, 2004-2021) предлагает при осуществлении в Основном корпусе поиска по запросу «что-то на расстоянии от 1 до 20 от оно, пот» (именительный падеж у оно выбран потому что запрос без указания падежа дает слишком много «шумовых» контекстов, в которых формы местоимения он приняты за формы местоимения оно).

Готовя эксперимент, мы исходили из следующей гипотезы: в предложениях, которые будут оценены как наиболее приемлемые, окажется нечто общее, что можно будет счесть фактором, способствующим употреблению анафорического оно после что-то, а в предложениях, которые будут оценены как наименее приемлемые, - нечто общее, что можно будет счесть за препятствующий фактор. 
В эксперименте приняло участие 135 человек. Каждый из участников оценил каждое предложение (или почти каждое: несколько участников пропустили по одному предложению) либо как правильное, либо как неправильное, либо как сомнительное. Соответственно, он дал каждому (или почти каждому) предложению либо 3 балла, либо 1 балл, либо 2 балла, ср. подобную систему перевода качественной оценки в количественную (Норман, 2006, с. 244-245).

В результате каждое предложение получило 135 (или почти 135) оценок. Ниже представлена таблица со средними баллами предложений (Таблица 1).

Таблица 1. Средние баллы предложений (предложения расположены в порядке убывания средних баллов)

\begin{tabular}{|c|c|c|c|}
\hline $\begin{array}{c}\text { № } \\
\text { предложения }\end{array}$ & $\begin{array}{c}\text { Средний балл } \\
\text { (среднее арифметическое } \\
\text { всех оценок, данных предложению) }\end{array}$ & $\begin{array}{c}\text { № } \\
\text { предложения }\end{array}$ & $\begin{array}{c}\text { Средний балл } \\
\text { (среднее арифметическое } \\
\text { всех оценок, данных предложению) }\end{array}$ \\
\hline 14 & 2,85 & 11 & 2,47 \\
\hline 13 & 2,74 & 6 & 2,44 \\
\hline 8 & 2,70 & 5 & 2,33 \\
\hline 9 & 2,61 & 12 & 2,26 \\
\hline 1 & 2,57 & 3 & 2,21 \\
\hline 7 & 2,56 & 4 & 2,12 \\
\hline 15 & 2,55 & 16 & 1,96 \\
\hline 2 & 2,50 & 10 & 1,94 \\
\hline
\end{tabular}

Можно теперь попытаться найти в предложениях, получивших высокие оценки, что-то такое, чего нет в предложениях, получивших низкие оценки, и выявить таким образом факторы, определяющие приемлемость/неприемлемость использования после что-то анафорического оно.

Впрочем, возникает вопрос о том, имеет ли смысл опираться в дальнейшем исследовании на оценки, данные участниками эксперимента. Нет ли риска, что респонденты присваивали предложениям баллы совершенно случайным образом? Может быть, у каждого из респондентов свой, абсолютно субъективный, взгляд на приемлемость рассматриваемых предложений, и, например, тот факт, что у 14-го предложения более высокая оценка, чем у 10-го, не отражает никаких языковых закономерностей? Представим, что имеется 16 предложений, каждому из которых совершенно бессистемно выставляется 135 оценок. В этом случае почти наверняка у одних предложений будет более высокий средний балл, а у других - более низкий. Не наш ли это случай?

Подобные сомнения вполне уместны, тем более что некоторые респонденты в ходе устного обсуждения результатов эксперимента отмечали, что, с их точки зрения, все примеры являются допустимыми. Нельзя продолжать исследование, не убедившись, что разница в средних оценках неслучайна, закономерна. Для того чтобы это сделать, обратимся к статистическому анализу и к понятию статистически значимого различия. Статистически значимое различие - такое различие, случайное возникновение которого маловероятно. Согласно общепринятым представлениям, различие является статистически значимым, если вероятность его случайности менее 0,05 .

Выявить наличие между выборками статистически значимых различий позволяет процедура однофакторного дисперсионного анализа, который использован и в настоящей работе (см. подробнее о дисперсионном анализе (Большев, 2017)). Выполнение расчетов осуществлено в рабочей среде R с применением функции аоv().

В результате установлено: вероятность того, что разница между всеми средними оценками случайна, меньше $2 \times 10^{-16}$, что существенно ниже уровня 0,05. Таким образом, разницу между средними оценками следует считать статистически значимой.

Однако применение однофакторного дисперсионного анализа дает возможность говорить лишь о том, что наличествует хотя бы одна пара предложений, в которой наблюдается статистически значимое различие между средними оценками.

Более точные данные позволяет получить процедура множественного сравнения групповых средних. Применяя эту процедуру (функция TukeyHSD() в рабочей среде R), удалось выяснить, что статистически значимой является разница между средними оценками в 48 из 120 возможных пар предложений, то есть в $40 \%$ пар.

Можно сделать вывод: носители языка действительно воспринимают отобранные для эксперимента предложения с точки зрения правильности употребления в них местоимения оно по-разному, и дальнейшее исследование различий в средних оценках с целью выявления факторов, влияющих на употребление оно, оправданно.

Очевидно, что искомые факторы могут быть связаны: 1) с характеристиками антецедента, то есть местоимения что-то; 2) с характеристиками анафора, то есть местоимения оно. Иными словами, носителю языка, оценивающему предложение, может нравиться/не нравиться нечто в антецеденте или в анафоре.

Факторы допустимости анафорического 'оно' после 'что-то': характеристики антецедента

Обращает на себя внимание, что в предложениях № 4, 16 и 10, получивших наиболее низкие средние оценки, местоимение что-то занимает позицию прямого дополнения, в то время как почти во всех остальных предложениях оно занимает позицию подлежащего.

Можно, таким образом, констатировать связь между синтаксической функцией что-то и допустимостью употребления после него анафорического оно. 
Однофакторный дисперсионный анализ показывает, что зависимость оценки от синтаксической позиции что-то случайна с вероятностью 0,000799. Это существенно ниже общепринятого уровня статистической значимости. Таким образом, связь средней оценки предложения с синтаксической позицией что-то неслучайна.

Лингвистическое объяснение выявленной зависимости можно найти в статье А. А. Кибрика (1987) «Фокусирование внимания и местоименно-анафорическая номинация»: «Прономинализация тесно связана с подлежащным статусом предшествующих наименований Референта. Если референт кодирован подлежащим, он очень часто после этого оказывается в фокусе внимания и легко прономинализуется» (разрядка А. А. Кибрика. - Э. Б.) (с. 84).

При дальнейшем анализе не обнаруживается каких-либо других характеристик антецедента, которые находились бы в статистически значимой связи со средними оценками предложений. Так, нельзя признать факторами, влияющими на употребление анафора, следующие характеристики антецедента:

1) наличие/отсутствие при антецеденте слов-распространителей (зависимость средней оценки от этой характеристики случайна с вероятностью 0,547 , что выше общепринятого уровня статистической значимости);

2) абстрактность/конкретность обозначаемого с помощью антецедента объекта (зависимость случайна с вероятностью 0,304);

3) фиксированность/нефиксированность обозначаемого с помощью антецедента объекта (зависимость случайна с вероятностью 0,138).

\section{Факторы допустимости анафорического 'оно' после 'что-то': характеристики анафора}

Однофакторный дисперсионный анализ показывает, что существует статистически значимая зависимость средней оценки предложения от характера осмысления референта местоимения оно в этом предложении: вероятность того, что эта зависимость случайна, равна 0,0274 .

Оказывается, статистически значимо более высокие оценки имеют те предложения, в которых референт местоимения оно связывается с идеей одушевленности и таинственности, а именно представляет собой конкретный объект, являющийся мистическим живым существом, или абстрактный объект, осмысляемый как живое существо. Те же предложения, в которых референт местоимения оно не связывается с идеей одушевленности и таинственности и вообще с какой бы то ни было особой идеей, имеют статистически значимо более низкие оценки.

Референт местоимения оно осмысляется как нечто таинственное и одушевленное в предложениях № $1,5,7$, $8,12,13,14,15$. Об этом свидетельствует наличие во всех этих предложениях при оно глаголов, обозначающих действия/состояния живых существ: задевать, возбуждать, обмануться, коснуться, броситься, сжимать и др.

Следует отметить, что с идеей таинственности и одушевленности обычно связывается референт субстантивированного оно (подробное рассмотрение вопроса о субстантивации местоимений, в частности личных, см. в (Шувалова, 2009)). Ср.:

Полное гнева, оно неслось... Оно близилось, и по мере того как близилось, время останавливало бег свой... Оно пришло... История прекратила течение свое (М. Е. Салтыков-Щедрин. История одного города).

Эти таинственные, возбуждающие волны предвещали появление чего-то прекрасного, и, наконец, возникало оно. Оно напоминало шелк на вид и на ощупь. Оно переливалось, было послушным, облегало тело...; оно сияло в толпе подобно драгоценному камню среди булыжников... (Булат Окуджава. Искусство кройки и житья).

Оно расхаживает так все дни напролет, сэр, - прошептал Пул. - Да и почти всю ночь тоже. Перестает только, когда приносят от аптекаря новый образчик (Р. Л. Стивенсон. Странная история доктора Джекила и мистера Хайда. Пер. с англ. И. Гуровой).

Cp. также перевод на русский язык названия романа С. Кинга “It”. Главный антагонист романа Оно некая таинственная сила, терроризирующая жителей вымышленного американского городка Дерри.

Поскольку местоимение оно во всех отобранных для эксперимента случаях кореферентно местоимению что-то, с идеей таинственности и одушевленности в предложениях № 1, 5, 7, 8, 12, 13, 14,15 связано не только оно, но и что-то. Не случайно при что-то в этих предложениях, как и при оно, употребляются глаголы, обозначающие действия живых существ: являться (вдруг являлось что-то резкое), обвиваться. Ср. также в предложении № 14: что-то тонкое, шершавое, плоское, ледяное, липкое и живое.

Как можно с лингвистической точки зрения объяснить установленную зависимость средней оценки предложения от характера осмысления референта местоимения оно?

Местоимение 3-го лица имеет, в сущности, двойную природу - указательно-концептуальную: указывает на уже упоминавшийся объект и одновременно актуализирует в сознании коммуникантов концепт, связанный с той номинацией, через которую этот объект уже упоминался.

Указательную природу местоимений 3-го лица предполагает их анафорическая функция: анафора - частный случай дейксиса, если дейксис понимать широко (ср. такое понимание дейксиса в (Крылов, 1989)). Концептуальную природу местоимений 3-го лица отметила Е. В. Падучева (2016): «Местоимение 3-го лица употребляется в ситуации, когда объект не просто упоминается повторно, а упоминается в презумпции неизменности связанного с ним концепта. Если же надо освободить объект от прежнего концепта, говорящий может упомянуть объект, не сообщая ему никакого концепта, - с помощью местоимения это».

Как кажется, в тех предложениях, в которых референт местоимения оно связывается с идеей одушевленности и таинственности, местоимение оно в полной мере реализует как свой указательный, так и свой концептуальный потенциал: не только указывает на уже упоминавшийся объект, но и повторно, вслед за местоимением что-то, выражает идею таинственности и одушевленности этого объекта. 
Поэтому предложения № $1,5,7,8,12,13,14,15$ и получили наиболее высокие оценки респондентов: в них функционирование местоимения оно более естественно, нормально, чем в остальных предложениях, где оно выполняет только указательную функцию, а значит, употребляется не в полном соответствии со своей природой.

Заметим, что связываемое с идеей одушевленности в предложениях № 1, 5, 7, 8, 12, 13, 14, 15 местоимение что-то (о том, что что-то в этих предложениях, как и оно, связывается с идеей одушевленности, см. выше), в отличие от парного ему местоимения кто-то, обычно с идеей одушевленности не связывается. Ср. мысль В. В. Виноградова (2001) о том, что в паре кто - что выражено «противопоставление лица - живого существа и предмета-вещи» (с. 275). Таким образом, если местоимение оно в указанных предложениях демонстрирует свое наиболее естественное, нормальное функционирование (и поэтому эти предложения оцениваются как наиболее приемлемые с точки зрения использования местоимения оно), то местоимение что-то, напротив, имеет в них непрототипическое употребление.

В предложениях № 2, 3, 4, 6, 9, 10, 11, 16, получивших сравнительно низкие оценки из-за того, что местоимение оно в них употреблено не в полном согласии с его природой, уместнее использовать в качестве анафора для что-то языковые выражения, предназначенные для выполнения только указательной функции. Ср., как можно трансформировать три предложения, получивших самые низкие оценки:

(4) *Он швырнул что-то на стол; тускло звякнуло оно, как полтинник.

(4') Он швырнул что-то на стол; тускло звякнуло то, что он швырнул, как полтинник.

(10) "Успех - это когда что-то строишь, и оно востребовано.

(10') Успех - это когда что-то строишь, и строимое (= то, что строишь) востребовано.

(16) *Чувствует, что надо говорить что-то такое веселое, бодрое, а как оно говорится, не знает.

(16’) Чувствует, что надо говорить что-то такое веселое, бодрое, а как это говорится, не знает.

После трансформации предложения не звучат как аномальные, потому что в них анафорическое выражение не претендует, будучи сугубо указательным средством, на особую концептуальную нагруженность.

Дальнейший анализ не обнаруживает каких-либо других характеристик анафора, которые находились бы в статистически значимой связи со средними оценками предложений. В частности, не может быть признана фактором, влияющим на употребление анафора, такая его характеристика, как наличие/отсутствие в той части предложения, где он употребляется, субъектно-предикатной инверсии. Вероятность того, что зависимость средней оценки от этой характеристики случайна, составляет 0,153.

\section{Заключение}

В результате исследования можно сделать следующие выводы. Существует как минимум два фактора, влияющих на употребление анафорического оно после что-то:

1) синтаксическая позиция местоимения что-то;

2) наличие/отсутствие у местоимения оно концептуальной нагрузки, обеспечивающей «естественное», полноценное употребление этого местоимения (во всех рассмотренных случаях эта нагрузка заключается в связи местоимения оно с идеей таинственности и одушевленности).

Первый фактор носит скорее формальный, а второй - скорее содержательный характер. Первый связан с характеристиками антецедента, второй - анафора.

Первый фактор, как кажется, имеет более широкую сферу действия, чем второй. Первый служит частной разновидностью более общего фактора, связанного с влиянием на употребление анафорического местоимения 3-го лица синтаксической позиции антецедента. Второй фактор представляется специфичным для пар «антецедент - неопределенное местоимение + анафор - местоимение 3-го лица», поскольку именно в таких парах возможно отсутствие у антецедента и, следовательно, у анафора концептуальной нагрузки.

Перспективы дальнейшего исследования проблемы мы видим в первую очередь в изучении тех возможностей выступать в роли антецедента местоимения 3-го лица, которые есть у местоимения кто-то. Кроме того, вполне возможно, что были отмечены далеко не все факторы, влияющие на употребление анафорического оно после что-то, так что перспективы касаются и дальнейшего, более детального анализа результатов проведенного эксперимента, а также проведения новых экспериментов с анафорической парой «что-то + оно».

\section{Источники | References}

1. Беглярова А. Л. Неопределенное местоимение как компонент образной структуры художественного текста // Вестник Адыгейского государственного университета. Серия 2: Филология и искусствоведение. 2011 . № 2.

2. Большев Л. Н. Дисперсионный анализ. 2017. URL: https://bigenc.ru/mathematics/text/1958678

3. Виноградов В. В. Русский язык (Грамматическое учение о слове). М.: Русский язык, 2001.

4. Горшкова Л. А. Семантика неопределенных местоимений в прозе Б. К. Зайцева // Вестник Волжского университета им. В. Н. Татищева. 2009. № 1.

5. Зализняк Анна А., Падучева Е. В. Русское «что-то» как дискурсивное слово // Компьютерная лингвистика и интеллектуальные технологии: сборник по материалам ежегодной международной конференции Диалог-2019 (г. Москва, 19 мая - 1 июня, 2019 г.). М.: РГГУ, 2019. 
6. Кибрик А. А. Фокусирование внимания и местоименно-анафорическая номинация // Вопросы языкознания. 1987. № 3.

7. Крылов С. А. О семантике местоименных слов и выражений // Русские местоимения: семантика и грамматика. Владимир: Владимир. гос. пед. ин-т, 1989.

8. Национальный корпус русского языка. 2004-2021. URL: https://ruscorpora.ru

9. Норман Б. Ю. Игра на гранях языка. М.: Флинта; Наука, 2006.

10. Падучева Е. В. Высказывание и его соотнесенность с действительностью (Референциальные аспекты семантики местоимений). М.: Наука, 1985.

11. Падучева Е. В. Указательные местоимения. Материалы для проекта корпусного описания русской грамматики (http://rusgram.ru). М., 2016.

12. Сигал К. Я. Анафорическое отношение: к уточнению понятия // Теоретические и прикладные аспекты изучения речевой деятельности. 2017. № 5 .

13. Синько Л. А. Референтные и дискурсивные свойства неопределенных местоимений // Вестник Адыгейского государственного университета. Серия 2: Филология и искусствоведение. 2011. № 2.

14. Третьякова О. Д. Функции неопределенных местоимений без показателя неопределенности (на материале славянских языков) // Вестник Московского университета. Серия 9: Филология. 2009. № 1.

15. Шмелев А. Д. Русский язык и внеязыковая действительность. М.: Языки славянской культуры, 2002.

16. Шувалова И. Е. К вопросу о субстантивации местоимений в русском языке. Межкатегориальная транспозиция местоимений // Вестник Челябинского университета. Серия: Филология. 2009. № 43 (181).

\section{Информация об авторах | Author information}

\section{RU Буров Эдуард Евгеньевич ${ }^{1}$}

${ }^{1}$ Иркутский государственный университет

EN Burov Eduard Evgenievich

${ }^{1}$ Irkutsk State University

1henyabur@mail.ru

\section{Информация о статье | About this article}

Дата поступления рукописи (received): 03.10.2021; опубликовано (published): 30.11.2021.

Ключевые слова (keywords): анафора; местоимение «что-то»; местоимение «оно»; факторы, влияющие на употребление анафорического местоимения; статистическая значимость; anaphora; pronoun “что-то (something)”; pronoun "оно (it)"; factors influencing the usage of an anaphoric pronoun; statistical significance. 